Original Article

\title{
The effect of a concomitant stroop task during sit-to-stand tasks on postural control
}

\author{
Yige Song, MS ${ }^{1)}$, Kazu Amimoto, RPT, PhD ${ }^{1)^{*}}$, Abdul Chalik Meidian, PhD ${ }^{1)}$ \\ 1) Department of Physical Therapy, Graduate School of Human Health Sciences, Tokyo Metropolitan \\ University: 7-2-10 Higashi-Ogu, Arakawa-ku, Tokyo 116-8551, Japan
}

\begin{abstract}
Purpose] This study aimed to explain the effect of a dual-task technology that utilizes motor and/or cognitive skills on the performance of major tasks, postural control, and gait consistency. [Participants and Methods] Eighteen healthy adults were divided into two groups: the single-word dual-task group and the control group (study 1). We enrolled 32 healthy adults to perform four-word Stroop (study 2) and sit-to-stand tasks simultaneously to determine the attentional demand for postural control and locomotion. [Results] The dynamic condition of postural control differed significantly between the single-task and single-word dual-task groups in Study 1. In Study 2, postural control in the four-word dual-task condition improved under both static and dynamic conditions. On comparing the results of studies 1 and 2, we found that during a four-word dual-task, healthy participants experienced a more significant decrease in postural sway than that experienced during the single-word dual-task. [Conclusion] Dual task of Stroop task with sit-to-stand could improve a postural control.

Key words: Dual-task, Postural control, Cognition
\end{abstract}

(This article was submitted Aug. 23, 2021, and was accepted Sep. 20, 2021)

\section{INTRODUCTION}

People must often perform several tasks simultaneously during their daily activities. A dual-task (DT) is a task that combines two motor tasks, or a motor and cognitive task, while keeping each target in mind $^{1,2)}$.However, the secondary task, which requires motor and/or cognitive skills, can impair an individual's performance, postural control, and gait consistency during the primary task $\mathrm{k}^{3-5)}$.

Dual-task training, which combines cognitive and motor training, enhances memory and postural function ${ }^{6}$. DT training can be beneficial in patients with various impairments. Studies have found that the postural function of patients with chronic stroke improved after DT training ${ }^{7,8)}$

We used DT procedures to evaluate the information-processing capacity of subjects performing two tasks simultaneously. If each task was completed correctly, the tasks were said to be independent, indicating that the attentional requirements of one task were not required to complete the other. However, if the participant's performance in one of the two tasks decreased compared to when the task is performed alone, this indicates that the attentional demands of the two tasks exceed the participant's attentional capacity ${ }^{9}$. Stapleton et al. suggested that a decrease in attentional capacity may be associated with an increase in attentional demands involved in performing a cognitive task under DT conditions ${ }^{10)}$. Ruffieux et al. claims that when more attentional resources are required or attentional capacities are limited, even simple motor skills can become difficult to perform simultaneously with an attention-demanding task. If processing capacities are exceeded, adding a concurrent task increases the overall attentional demands and may cause interference between the two tasks ${ }^{11)}$. Therefore, employing specific secondary task practice is important to acquire skills under DT conditions ${ }^{12)}$, as the type of secondary task can influence postural control in adults ${ }^{13}$. Some studies claim that the complexity and type of secondary tasks performed

*Corresponding author. Kazu Amimoto (E-mail: amimoto@tmu.ac.jp)

(C2021 The Society of Physical Therapy Science. Published by IPEC Inc.

(c) (1) $\odot$ This is an open-access article distributed under the terms of the Creative Commons Attribution Non-Commercial No DerivaCC BY NC ND tives (by-nc-nd) License. (CC-BY-NC-ND 4.0: https://creativecommons.org/licenses/by-nc-nd/4.0/) 
while performing motor tasks affect postural control. The type of secondary task or domain of information processed while performing the secondary task may impact the patients' balance during DT training while performing a motor task ${ }^{14,15)}$.

Hiyamizu et al. demonstrated that the Stroop test is a cognitive task used to assess the cognitive control and is commonly used in neuropsychology and cognitive neuroscience. Furthermore, their findings show that the after Stroop task training resulted in increased smoothness in cognitive activity while performing motor tasks in daily life ${ }^{16)}$. In the Stroop task, the participants name the ink color that the name of a color is written in. If the color and word (e.g., "red" in red ink) are congruent, the task is straightforward. However, the task becomes more complex with when the color and meaning of the word are incongruous (e.g., "Blue" in red ink) ${ }^{17)}$. This is because reading is a more practical and automatic ability than naming colors, so the participants must exert attentional control to overcome their tendency towards reacting to the word rather than to the color $^{18,19)}$.

The researcher used the dual-task paradigm and found an interaction between posture control and cognitive tasks when they are completed simultaneously. They pointed out that posture control does not happen automatically but requires cognitive participation ${ }^{11-13)}$. Stroop test is proven to be used to assess cognitive ability ${ }^{16)}$.

Accordingly, we increased the difficulty of Stroop test to explore the interaction between cognition and posture control. Two complementary studies were conducted within this complex context to investigate the effect of the DT of more difficult Stroop tasks on postural control in healthy participants. In Study 1, we explored the effects of a Stroop task on posture among healthy adults by comparing single-task and DT conditions. In Study 2, we increased the difficulty of the Stroop task.

\section{PARTICIPANTS AND METHODS}

Fifty healthy participants were involved in this study. We conducted a non-clinical quasi-experimental design with singleblind allocation concealment. Eighteen healthy adults were divided into two groups: the single-word dual-task group (SDT) and the control group. A flow diagram is shown in Fig. 1A (Study 1). In Study 1, participants were randomly allocated to the SDT $(n=9)$ or control groups, respectively $(n=9)$. Participants in the SDT group were asked to perform a single-word Stroop task, while the control group only watched the Stroop task without saying any words.

The inclusion criteria were as follows: (1) 20 years of age or older; (2) no neurologic or musculoskeletal diagnoses, such as orthopedic involvement or significant visual or auditory impairments. If they conformed to the inclusion criteria, the participants were randomly allocated to each group. We explained the study protocol to the participants before obtaining informed consent. The study was approved by the Research Ethics Committee of the Tokyo Metropolitan University (No. 19105).

Study 2 has the same inclusion criteria as Study 1. Thirty-two healthy adults were divided into single-task and DT groups. A flow diagram is shown in Fig. 1B (Study 2). In Study 2, the participants were randomly allocated to either the four-word DT group $(n=16)$ or the single-task group $(n=16)$.

The intervention lasted for $1 \mathrm{~min}$. An unstable cushion was placed on the chair seat. During the single-task and DT conditions, the participants were asked to keep changing from sitting to standing as a motor task. In the single-task condition, the participants were asked to go from sitting to standing at a set speed using a metronome without using their upper limbs, and only watch the Stroop task without saying any words. All the previous procedures were repeated in the DT condition; however, the participants had to perform the Stroop test while repeatedly going from sitting to standing.

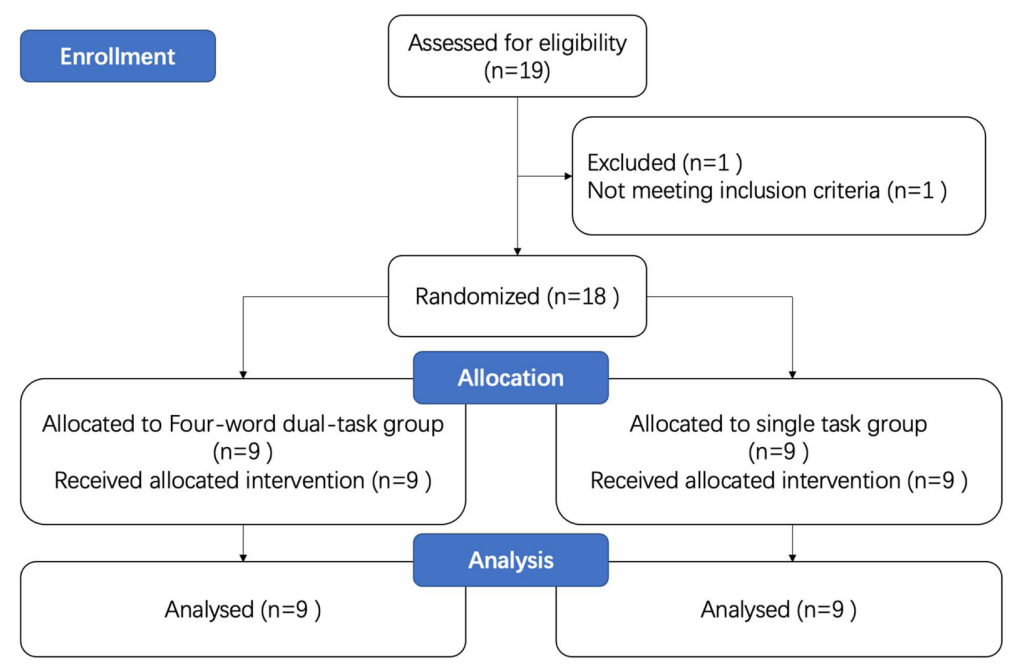

Fig. 1A. Flow diagram in Study 1. 
Four different words appeared on the monitor. The ink color matched three of the words (color names), while one was not matched (e.g., "red" in yellow letters). Twelve pages were added during the experiment. The stimulus was displayed in front of the participants on a 2-meter computer with a white background. The subjects were asked to identify and state the color of the mismatched word. The time interval between the inserted words randomly changed between $100 \mathrm{~ms}$ and $200 \mathrm{~ms}$ to avoid a pattern being noticed.

Participants tried to maintain their balance while standing on a pressure plate (ANIMA GRAVICORDER G-620, Tokyo, Japan) with their hands crossed in front of their chest to maintain a safe and relaxed stance. The participants were given a brief orientation to the setup to find a suitable position for their feet on the standing area. The participants' foot positions were marked on the plate to ensure reproducibility of the position.

Each group completed the standing balance test, which required four conditions. In the static standing test, participants were asked to maintain their posture with their eyes open or closed while remaining as still as possible. In the dynamic standing test, participants were asked to incline their posture forwards and/or backwards. Participants were required to incline forward or backward while keeping their back as straight as possible, rather than bending their upper body. Each condition required that the participants look at a point two m away at eye level for $30 \mathrm{~s}$. Standing balance tests were completed before and after the intervention.

We used two-way repeated-measures analysis of variance to compare changes in outcome between the groups at two different time points. The groups and times were used to assess the presence or absence of interaction among the factors. If an interaction was present, a simple main effect test was performed. All analyses were conducted using the Statistical Package for Social Sciences (SPSS) version 26.0 (IBM Corp., NY, USA), and significance levels were set at $\mathrm{p}<0.05$.

\section{RESULTS}

Table 1 presents the demographic characteristics of the study population. Eighteen participants were eligible, of which 11 were men and 7 were women). The experiment and control groups had average ages of $26.00 \pm 5.43$ and $27.78 \pm 5.12$ years, respectively.

There were no differences in demographic characteristics such as gender, age, height, or weight between the groups. None of the participants in either group experienced severe adverse events during the study period.

The outcomes are shown in Table 2. None of the outcomes of the main effects of the groups were significant, except for MY and LNG in the forward condition, and MY in the backward condition. The effect of time was not significant. No

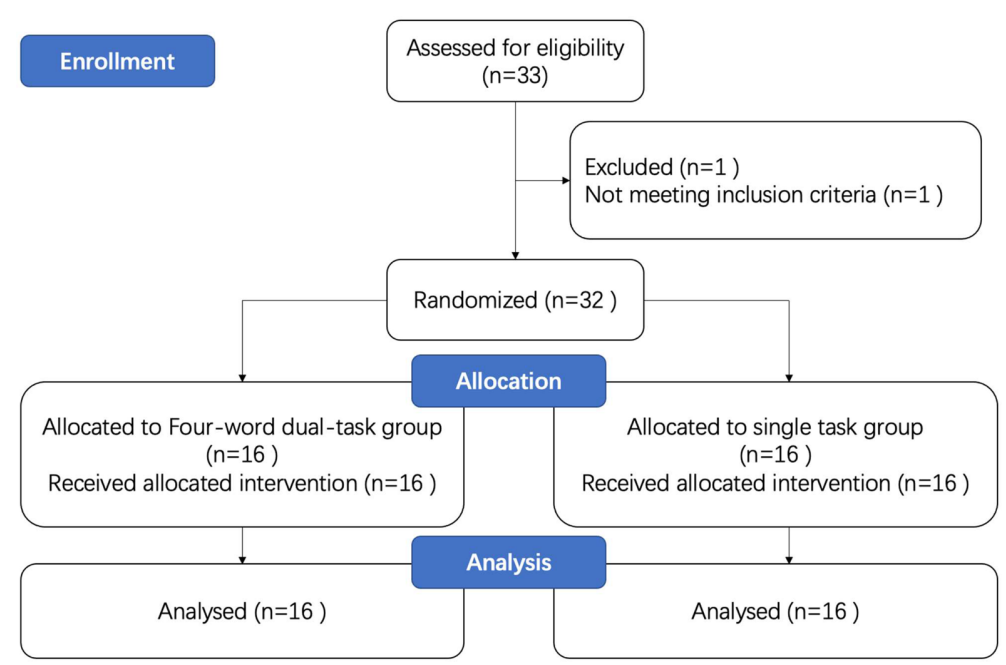

Fig. 1B. Flow diagram in Study 2.

Table 1. Demographic data of the two groups in Study 1

\begin{tabular}{lccc}
\hline & SDT $(\mathrm{n}=9)$ & Control $(\mathrm{n}=9)$ & $\mathrm{p}$-value \\
\hline Age (years) & $26.0 \pm 5.4$ & $27.8 \pm 5.1$ & 0.37 \\
Gender $(\mathrm{M} / \mathrm{F})$ & $5 / 4$ & $6 / 3$ & \\
Height $(\mathrm{cm})$ & $164.1 \pm 7.8$ & $163.22 \pm 10.44$ & 0.85 \\
Weight $(\mathrm{kg})$ & $58.3 \pm 4.8$ & $60.9 \pm 11.8$ & 0.61 \\
\hline
\end{tabular}


significant interactions were observed.

Table 3 presents the demographic characteristics of the study population. A total of 32 people were eligible for the study, which included 22 males and 10 females. The experiment and control groups had average ages of $28.38 \pm 5.02$ and $28.13 \pm$ 4.99 years, respectively.

There were no differences in demographic characteristics such as gender, age, height, or weight between the groups. None of the participants in either group experienced severe adverse events during the study period.

The outcomes are shown in Table 4. The outcomes of the main effects of the groups were not significant, except for the RMS of the eyes open, forward, and backward conditions. The primary effect of time was not significant, except in the MY of the forward condition, and MY, LNG, and RMS of the backward condition. The interactions were significant in the eyes open-LNG, eyes-closed LNG, forward-MY, and backward-MY. The other outcomes showed no significant interactions.

\section{DISCUSSION}

The present study explored the effect of adding the difficulty to Stroop task on the postural control by comparing the training with Stroop task and without Stroop task on healthy participations.

The study is to explore the effect of the Stroop task on posture control. We used the COP monitor to evaluate the postural control indicated by the COP-MX, COP-MY, COP-length and COP-RMS. We found that the dynamic condition of postural control benefitted significantly between single-task and SDTs in Study 1 and postural control benefitted more from single word DTs. In Study 2, comparing the individuals in the single-task and four-word DT conditions, postural control of the

Table 2. Effect of intervention between the two groups at baseline in Study 1

\begin{tabular}{lccc}
\hline & Experiment $(\mathrm{n}=16)$ & Control $(\mathrm{n}=16)$ & $\mathrm{p}$-value \\
\hline Age $($ years $)$ & $28.4 \pm 5.0$ & $28.1 \pm 5.0$ & 0.89 \\
Gender $(\mathrm{M} / \mathrm{F})$ & $10 / 6$ & $12 / 4$ & \\
Height $(\mathrm{cm})$ & $166.3 \pm 8.2$ & $167.3 \pm 7.2$ & 0.73 \\
Weight $(\mathrm{kg})$ & $62.5 \pm 12.7$ & $66.1 \pm 12.8$ & 0.41 \\
\hline$* \mathrm{p}<0.06, * * \mathrm{p}<0.01, * * * \mathrm{p}<0.001$. & &
\end{tabular}

Table 3. Demographic data of the two groups in study 2

\begin{tabular}{|c|c|c|c|c|c|c|c|}
\hline \multirow[b]{3}{*}{ Variable } & \multicolumn{4}{|c|}{ Data of two groups before and after intervention } & \multirow{3}{*}{ Group } & \multirow{3}{*}{ Time } & \multirow{3}{*}{ Group $\times$ Time } \\
\hline & \multicolumn{2}{|c|}{ SDT group } & \multicolumn{2}{|c|}{ Control group } & & & \\
\hline & Pre-test & Post-test & Pre-test & Post-test & & & \\
\hline \multicolumn{8}{|l|}{ Static } \\
\hline Eyes open MX & $-0.76 \pm 0.89$ & $-0.53 \pm 1.10$ & $0.12 \pm 0.59$ & $0.12 \pm 0.69$ & & & \\
\hline Eyes open MY & $-2.64 \pm 1.96$ & $-3.02 \pm 1.83$ & $-2.44 \pm 1.30$ & $-2.25 \pm 1.65$ & & & \\
\hline Eyes open LNG & $16.27 \pm 6.08$ & $16.03 \pm 6.08$ & $17.21 \pm 5.10$ & $19.78 \pm 7.02$ & & & \\
\hline Eyes open RMS & $0.59 \pm 0.45$ & $0.58 \pm 0.44$ & $0.69 \pm 0.49$ & $0.89 \pm 0.73$ & & & \\
\hline Eyes closed MX & $-0.50 \pm 0.93$ & $-0.56 \pm 0.98$ & $0.02 \pm 0.45$ & $0.04 \pm 0.71$ & & & \\
\hline Eyes closed MY & $-2.72 \pm 1.72$ & $-2.92 \pm 2.11$ & $-2.32 \pm 1.18$ & $-2.29 \pm 1.77$ & & & \\
\hline Eyes closed LNG & $20.26 \pm 7.51$ & $18.95 \pm 6.72$ & $21.07 \pm 7.63$ & $26.53 \pm 10.28$ & & & \\
\hline Eyes closed RMS & $0.43 \pm 0.23$ & $0.37 \pm 0.16$ & $0.46 \pm 0.15$ & $0.50 \pm 0.18$ & & & \\
\hline \multicolumn{8}{|l|}{ Dynamic } \\
\hline Forward MX & $-0.49 \pm 1.24$ & $-0.35 \pm 1.35$ & $-0.25 \pm 0.76$ & $-0.31 \pm 0.73$ & & & \\
\hline Forward MY & $3.83 \pm 1.32$ & $4.27 \pm 1.37$ & $2.77 \pm 2.51$ & $2.79 \pm 2.64$ & $*$ & & \\
\hline Forward LNG & $25.85 \pm 9.11$ & $24.22 \pm 8.81$ & $29.59 \pm 11.95$ & $31.57 \pm 13.94$ & $*$ & & \\
\hline Forward RMS & $1.04 \pm 0.60$ & $1.07 \pm 0.89$ & $0.98 \pm 0.51$ & $1.04 \pm 0.55$ & & & \\
\hline Backward MX & $-1.04 \pm 1.12$ & $-1.14 \pm 1.02$ & $-0.05 \pm 0.82$ & $-0.22 \pm 0.99$ & & & \\
\hline Backward MY & $-7.70 \pm 2.48$ & $-8.07 \pm 2.93$ & $-5.19 \pm 1.74$ & $-5.07 \pm 2.13$ & $* *$ & & \\
\hline Backward LNG & $28.71 \pm 14.44$ & $28.50 \pm 13.05$ & $33.03 \pm 11.23$ & $34.21 \pm 14.45$ & & & \\
\hline Backward RMS & $0.69 \pm 0.33$ & $0.65 \pm 0.28$ & $0.79 \pm 0.58$ & $0.80 \pm 0.75$ & & & \\
\hline
\end{tabular}

MX: mean value of COP in the left-right direction; MY: mean value of COP in the anterior-posterior direction; LNG: Length of the trajectory at the COP; RMS: Root Mean Square.

${ }^{*} \mathrm{p}<0.05, * * \mathrm{p}<0.01, * * *<0.001$. 
Table 4. Effect of intervention between the two groups at baseline in Study 2

\begin{tabular}{|c|c|c|c|c|c|c|c|}
\hline \multirow[b]{3}{*}{ Variable } & \multicolumn{4}{|c|}{ Data of two groups before and after intervention } & \multirow[b]{2}{*}{ Group } & \multirow{3}{*}{ Time } & \multirow{3}{*}{ Group $\times$ Time } \\
\hline & \multicolumn{2}{|c|}{ Experiment group } & \multicolumn{2}{|c|}{ Control group } & & & \\
\hline & Pre-test & Post-test & Pre-test & Post-test & & & \\
\hline \multicolumn{8}{|l|}{ Static } \\
\hline Eyes open MX & $0.15 \pm 0.82$ & $0.21 \pm 0.92$ & $0.00 \pm 0.58$ & $-0.18 \pm 0.64$ & & & \\
\hline Eyes open MY & $-1.95 \pm 1.91$ & $-1.15 \pm 1.87$ & $-1.70 \pm 1.58$ & $-1.50 \pm 2.14$ & & & \\
\hline Eyes open LNG & $33.83 \pm 8.41$ & $31.98 \pm 7.82$ & $33.95 \pm 7.08$ & $35.05 \pm 7.06$ & & & $* *$ \\
\hline Eyes open RMS & $0.70 \pm 0.33$ & $0.53 \pm 0.29$ & $0.90 \pm 0.51$ & $1.06 \pm 0.59$ & * & & \\
\hline Eyes closed MX & $0.11 \pm 0.71$ & $-0.27 \pm 0.96$ & $-0.05 \pm 0.52$ & $-0.22 \pm 0.63$ & & & \\
\hline Eyes closed MY & $-1.89 \pm 1.95$ & $-1.21 \pm 1.82$ & $-1.67 \pm 1.52$ & $-1.59 \pm 1.95$ & & & \\
\hline Eyes closed LNG & $37.20 \pm 10.02$ & $33.53 \pm 8.24$ & $36.38 \pm 9.07$ & $38.36 \pm 8.84$ & & & $* *$ \\
\hline Eyes closed RMS & $0.65 \pm 0.45$ & $0.52 \pm 0.34$ & $0.58 \pm 0.41$ & $0.61 \pm 0.45$ & & & \\
\hline \multicolumn{8}{|l|}{ Dynamic } \\
\hline Forward MX & $0.04 \pm 0.76$ & $-0.18 \pm 0.88$ & $-0.11 \pm 0.60$ & $-0.35 \pm 0.74$ & & & \\
\hline Forward MY & $2.55 \pm 2.84$ & $3.50 \pm 2.63$ & $3.07 \pm 2.74$ & $3.21 \pm 2.63$ & & $* *$ & $* *$ \\
\hline Forward LNG & $43.27 \pm 11.65$ & $42.74 \pm 10.35$ & $42.01 \pm 9.87$ & $43.13 \pm 9.55$ & & & \\
\hline Forward RMS & $1.11 \pm 0.58$ & $1.10 \pm 0.72$ & $1.32 \pm 0.70$ & $1.67 \pm 1.30$ & $*$ & & \\
\hline Backward MX & $0.06 \pm 0.98$ & $-0.03 \pm 1.01$ & $0.06 \pm 0.81$ & $-0.25 \pm 0.95$ & & & \\
\hline Backward MY & $-5.28 \pm 1.51$ & $-6.04 \pm 1.64$ & $-5.29 \pm 1.50$ & $-5.18 \pm 1.74$ & & $* *$ & $* *$ \\
\hline Backward LNG & $44.62 \pm 10.39$ & $42.09 \pm 8.81$ & $46.30 \pm 10.36$ & $45.66 \pm 10.87$ & & & \\
\hline Backward RMS & $1.08 \pm 0.69$ & $0.70 \pm 0.40$ & $1.31 \pm 0.96$ & $1.13 \pm 0.78$ & $*$ & $* *$ & \\
\hline
\end{tabular}

MX: mean value of COP in the left-right direction; MY: mean value of COP in the anterior-posterior direction; LNG: Length of the trajectory at the COP; RMS: Root Mean Square.

${ }^{*} \mathrm{p}<0.05, * * \mathrm{p}<0.01, * * * \mathrm{p}<0.001$.

DT condition was improved under static and dynamic conditions. However, comparing the results of Study 1 and Study 2 in healthy participants indicated that performing a four-word DT produced a significant decrease in postural sway that was better than that of the single-word DT.

The 'posture-first' principle suggests that cognitive tasks cause increased balance interference, as balance is prioritized $^{20,21)}$. Vaillant et al. included 68 osteoporotic females $>70$ years of age in a study on dual-tasking balance training and found that balance improved after the DT in the one-leg balance test and Timed Up and Go test in the single-task and DT groups. The DT group exercised while performing standardized cognitive tasks, such as reciting poems, counting out loud in increments of two, three, or five, and reciting lists of objects or places ${ }^{22}$. Pellecchia et al. assessed the effects of DTs on postural stability among healthy young participants, and the cognitive task was counting backward in increments of 3 . Based on their results, postural control was significantly improved in the DT group compared with that of the control group ${ }^{23)}$. Hiyamizu et al. included forty-three subjects (all $>65$ years old) who were randomly assigned to either a DT or control group. The Stroop task was set as the cognitive task in the DT group. Their results suggest that DT balance training in older adults improves DT performance in terms of standing postural control ${ }^{16)}$. We used the Stroop task in Study 1 and found that our findings are similar to those of Hiyamizu et al, who discovered that postural control in healthy adults improved after DT training compared to that observed after single-task conditions. In Study 2, we used the more difficult Stroop task and found that postural control improved after DT training, and the participants' postural control was better than that observed in Study 1. The Stroop task is a cognitive task that is often used in neuropsychology and cognitive neuroscience to assess the cognitive control. According to research on brain imaging, a brain area related to working memory, such as the supra-marginal bilateral inferior frontal regions, may be stimulated. As a result, this area is assumed to contain a component required for smooth standing postural control ${ }^{18)}$. The findings of this study indicate that postural control and cognitive function are not independent systems, which further supports the posture-first principle.

The physiological explanation for our findings is that cerebral processing under DT conditions changes the way the central nervous system controls postural stability. Balance is preserved under normal circumstances by integrating sensory information from the visual, vestibular, and somatosensory systems ${ }^{24,25)}$. The input is obtained from limb positioning and transmitted to the basal ganglia. This signal is integrated with planned actions developed in the premotor and supplementary motor cortices in the cerebellum. Visual and somatosensory inputs typically provide the majority of information required to maintain postural stability ${ }^{26)}$.

To explain the preservation or improvement in postural control during the DT condition, Vuillerme and Nafati suggested two additional hypotheses. The first hypothesis proposes that increased concentration during a reaction-timed cognitive task 
results in increased muscle stiffness and improved postural control ${ }^{27)}$. Hunter et al. supported this theory by demonstrating that medial-lateral COP movement was reduced during a balance test in participants who simultaneously performed visual cognitive tasks ${ }^{28)}$. Our results also confirmed this view, the postural control of participations improved after the dual-task training.

The second hypothesis proposes that DT conditions improve sensory-motor control ${ }^{29)}$. The present study revealed that postural stability was improved following participants on performing the dual task. By integrating a secondary cognitive task into the DT system, we can reflect sports situations better by the day, forcing individuals to focus on the secondary cognitive task while having postural stability to facilitate the automatic processes described previously ${ }^{27)}$. Moreover, our results confirm a previous study that indicated postural stability was improved by Stroop task. Moreover, our result showed that after difficulty Stroop task postural control was improved better than simple Stroop task.

According to the task integration hypothesis, participants can improve task-coordination skills by practicing two tasks simultaneously (instead of one at a time) ${ }^{30}$ ). One potential explanation may be that improving postural control requires effective integration and coordination of the two tasks learned during DT training.

Silsupadol et al. demonstrated the benefits of dual-tasking according to the task integration hypothesis, which states that practicing two tasks simultaneously improves task coordination skills ${ }^{30}$ ). Similarly, Kramer et al. observed significant benefits in the priority variable benefits and suggested that participants should learn to coordinate between two tasks under variable priority training conditions ${ }^{31}$. In addition, some brain centers with DT processing have shown reduced activation following practice, which suggests that lower processing power is required ${ }^{32}$. Several studies have also proposed DTs as cognitive therapy in patients with attention deficiencies and cognitive impairments ${ }^{33,34)}$. Wollesen et al. found that DT training systems can also improve cognitive skills ${ }^{35}$. According to Hiyamizu, improvements in cognitive efficiency can lead to a smoothing of cognitive activities while maintaining static and dynamic postures, which may prevent participants from falling ${ }^{16)}$. Our findings are similar to those of Hiyamizu who found that postural control in healthy adults improved after DT training compared to single-task conditions.

Huxhold et al. observed that a perceptual-motor task was facilitated when the practice was paired with a difficult secondary task, but not when the practice was paired with an easy secondary task. The authors suggested that the difficulty of the secondary task induced a positive vigilance effect, which benefitted the primary task performance, which was measured at delayed retention. In other words, participants may have increased the use of attentional resources when handling difficult secondary tasks. Increased cognitive effort during practice is a well-recognized factor that benefits motor learning ${ }^{36)}$.

This study has several limitations. The first is that we did not assign cognitive tasks, choosing to only observe motor and motor cognitive tasks. Therefore, it is unclear whether the postural control training was effective under cognitive task conditions. The second limitation was that we included healthy individuals in this study. However, it is noteworthy that intervention with DT balance education improved postural control, even in healthy individuals.

In conclusion, the main issue addressed in this experiment was the measurement of postural stability during different DT conditions. In DT conditions under static and dynamic conditions, participants exhibit improved postural control in single-task conditions, which aligned with the posture-first principle. A significant decrease in postural sway was observed in participants who were subjected to four-word DT conditions, which was larger than that observed in the simple DT condition.

As a clinical implication, we suggested further study involving patients by difficulty cognitive task training to actual hemiparesis and stroke patients. Further studies are needed to explore the interaction between postural control and cognition before implementing it to patients.

\section{Conflict of interest}

There are no conflicts of interest to declare.

\section{REFERENCES}

1) Broeder S, Nackaerts E, Nieuwboer A, et al.: The effects of dual tasking on handwriting in patients with Parkinson's disease. Neuroscience, 2014, 263: 193-202. [Medline] [CrossRef]

2) Plummer P, Eskes G: Measuring treatment effects on dual-task performance: a framework for research and clinical practice. Front Hum Neurosci, 2015, 9: 225. [Medline] [CrossRef]

3) Bloem BR, Grimbergen YA, van Dijk JG, et al.: The "posture second" strategy: a review of wrong priorities in Parkinson's disease. J Neurol Sci, 2006, 248: 196-204. [Medline] [CrossRef]

4) Brauer SG, Morris ME: Can people with Parkinson's disease improve dual tasking when walking? Gait Posture, 2010, 31: 229-233. [Medline] [CrossRef]

5) Fernandes Â, Coelho T, Vitória A, et al.: Standing balance in individuals with Parkinson's disease during single and dual-task conditions. Gait Posture, 2015, 42: 323-328. [Medline] [CrossRef]

6) Norouzi E, Vaezmosavi M, Gerber M, et al.: Dual-task training on cognition and resistance training improved both balance and working memory in older people. Phys Sportsmed, 2019, 47: 471-478. [Medline] [CrossRef]

7) Tetik Aydoğdu Y, Aydoğdu O, İnal HS: The effects of dual-task training on patient outcomes of institutionalized elderly having chronic stroke. Dement Geriatr Cogn Disord Extra, 2018, 8: 328-332. [Medline] [CrossRef]

8) Pang MY, Yang L, Ouyang H, et al.: Dual-task exercise reduces cognitive-motor interference in walking and falls after stroke. Stroke, 2018, 49: 2990-2998. 
[Medline] [CrossRef]

9) Brauer SG, Broome A, Stone C, et al.: Simplest tasks have greatest dual task interference with balance in brain injured adults. Hum Mov Sci, 2004, 23: 489-502. [Medline] [CrossRef]

10) Stapleton T, Ashburn A, Stack E: A pilot study of attention deficits, balance control and falls in the subacute stage following stroke. Clin Rehabil, 2001, 15: 437-444. [Medline] [CrossRef]

11) Ruffieux J, Keller M, Lauber B, et al.: Changes in standing and walking performance under dual-task conditions across the lifespan. Sports Med, 2015, 45: 1739-1758. [Medline] [CrossRef]

12) Fu WT, Anderson JR: Dual learning processes in interactive skill acquisition. J Exp Psychol Appl, 2008, 14: 179-191. [Medline] [CrossRef]

13) Bherer L, Kramer AF, Peterson MS, et al.: Transfer effects in task-set cost and dual-task cost after dual-task training in older and younger adults: further evidence for cognitive plasticity in attentional control in late adulthood. Exp Aging Res, 2008, 34: 188-219. [Medline] [CrossRef]

14) Bloem BR, Valkenburg VV, Slabbekoorn M, et al.: The multiple tasks test. Strategies in Parkinson's disease. Exp Brain Res, 2001, 137: 478-486. [Medline] [CrossRef]

15) Galletly R, Brauer SG: Does the type of concurrent task affect preferred and cued gait in people with Parkinson's disease? Aust J Physiother, 2005, 51: 175-180. [Medline] [CrossRef]

16) Hiyamizu M, Morioka S, Shomoto K, et al.: Effects of dual task balance training on dual task performance in elderly people: a randomized controlled trial. Clin Rehabil, 2012, 26: 58-67. [Medline] [CrossRef]

17) Stroop JR: Studies of interference in serial verbal reactions. J Exp Psychol, 1935, 18: 643-662. [CrossRef]

18) Egner T, Hirsch J: The neural correlates and functional integration of cognitive control in a Stroop task. Neuroimage, 2005, 24: 539-547. [Medline] [CrossRef]

19) van Veen V, Carter CS: Separating semantic conflict and response conflict in the Stroop task: a functional MRI study. Neuroimage, 2005, 27: 497-504. [Medline] [CrossRef]

20) Andersson G, Hagman J, Talianzadeh R, et al.: Effect of cognitive load on postural control. Brain Res Bull, 2002, 58: 135-139. [Medline] [CrossRef]

21) Yogev-Seligmann G, Hausdorff JM, Giladi N: Do we always prioritize balance when walking? Towards an integrated model of task prioritization. Mov Disord, 2012, 27: 765-770. [Medline] [CrossRef]

22) Vaillant J, Vuillerme N, Martigné P, et al.: Balance, aging, and osteoporosis: effects of cognitive exercises combined with physiotherapy. Joint Bone Spine, 2006, 73: 414-418. [Medline] [CrossRef]

23) Pellecchia GL: Dual-task training reduces impact of cognitive task on postural sway. J Mot Behav, 2005, 37: 239-246. [Medline] [CrossRef]

24) Broglio SP, Tomporowski PD, Ferrara MS: Balance performance with a cognitive task: a dual-task testing paradigm. Med Sci Sports Exerc, 2005, 37: 689-695. [Medline] [CrossRef]

25) Vuillerme N, Nougier V: Attentional demand for regulating postural sway: the effect of expertise in gymnastics. Brain Res Bull, 2004, 63: 161-165. [Medline] [CrossRef]

26) Riemann BL, Guskiewicz KM: Effects of mild head injury on postural stability as measured through clinical balance testing. J Athl Train, 2000 , 35: 19-25. [Medline]

27) Vuillerme N, Nafati G: How attentional focus on body sway affects postural control during quiet standing. Psychol Res, 2007, 71: 192-200. [Medline] [CrossRef]

28) Hunter MC, Hoffman MA: Postural control: visual and cognitive manipulations. Gait Posture, 2001, 13: 41-48. [Medline] [CrossRef]

29) Vuillerme N, Nougier V, Teasdale N: Effects of a reaction time task on postural control in humans. Neurosci Lett, 2000, 291: 77-80. [Medline] [CrossRef]

30) Silsupadol P, Shumway-Cook A, Lugade V, et al.: Effects of single-task versus dual-task training on balance performance in older adults: a double-blind, randomized controlled trial. Arch Phys Med Rehabil, 2009, 90: 381-387. [Medline] [CrossRef]

31) Kramer AF, Larish JF, Strayer DL: Training for attentional control in dual task settings: a comparison of young and old adults. J Exp Psychol Appl, 1995, 1: 50-76. [CrossRef]

32) Erickson KI, Colcombe SJ, Wadhwa R, et al.: Training-induced functional activation changes in dual-task processing: an FMRI study. Cereb Cortex, 2007, 17: 192-204. [Medline] [CrossRef]

33) Choi JH, Kim BR, Han EY, et al.: The effect of dual-task training on balance and cognition in patients with subacute post-stroke. Ann Rehabil Med, 2015, 39: 81-90. [Medline] [CrossRef]

34) Pichierri G, Wolf $\mathrm{P}$, Murer K, et al.: Cognitive and cognitive-motor interventions affecting physical functioning: a systematic review. BMC Geriatr, 2011, 11: 29-29. [Medline] [CrossRef]

35) Bettina Wollesen CVR: Training effects on motor-cognitive dual-task performance in older adults. 2014, 5: 24.

36) Huxhold O, Li SC, Schmiedek F, et al.: Dual-tasking postural control: aging and the effects of cognitive demand in conjunction with focus of attention. Brain Res Bull, 2006, 69: 294-305. [Medline] [CrossRef] 